https://helda.helsinki.fi

\title{
Using Activity Theory to transform medical work and learning
}

\section{Engeström, Yrjö}

2021-01-02

Engeström , Y \& Pyörälä , E 2021 , ' Using Activity Theory to transform medical work and learning ' , Medical Teacher , vol. 43 , no. 1 , pp. 7-13 . https://doi.org/10.1080/0142159X.2020.1795105

http://hdl.handle.net/10138/332574

https://doi.org/10.1080/0142159X.2020.1795105

acceptedVersion

Downloaded from Helda, University of Helsinki institutional repository.

This is an electronic reprint of the original article.

This reprint may differ from the original in pagination and typographic detail.

Please cite the original version. 


\section{Using Activity Theory to transform medical work and learning}

Medical Teacher

To cite this article: Yrjö Engeström \& Eeva Pyörälä (2020): Using activity theory to transform medical work and learning, Medical Teacher

DOI: 10.1080/0142159X.2020.1795105

To link to this article: https://doi.org/10.1080/0142159X.2020.1795105

Authors:

Yrjö Engeström, Center for Research on Activity, Development and Learning, University of Helsinki, Finland, ORCID https://orcid.org/0000-0002-6949-4278

Eeva Pyörälä, Center for University Teaching and Learning, University of Helsinki, Finland, ORCID https://orcid.org/0000-0002-2474-2434

Corresponding author:

Yrjö Engeström, Center for Research on Activity, Development and Learning, University of Helsinki, P.O. Box 9, 00014 University of Helsinki, Finland, e-mail yrjo.engestrom@helsinki.fi 


\begin{abstract}
This article introduces key concepts of activity theory and expansive learning. Expansive learning builds on the foundational ideas of the cultural-historical activity theory (CHAT). It is a research approach designed for studying the complexities and contradictions in authentic workplace environments. Change Laboratory is a formative intervention method developed for studying workplaces in transition and for stimulating collaborative efforts to design improved patterns of activity. We present concrete examples of formative interventions in healthcare, where good patient care was compromised by the fragmentation of care and disturbances in collaboration between the healthcare experts. This implies that physicians are challenged to develop collaborative and transformative expertise. We present three spearheads into a zone of proximal development, representing opportunities for change of medical expertise: (1) reconceptualizing expertise as object-oriented and contradiction-driven activity systems, (2) pursuing expertise as negotiated knotworking, and (3) building expertise as expansive learning. While medical expertise needs to expand, medical education must also look for ways to evolve and meet the challenges of the surrounding society. We call for adopting an interventionist approach for developing medical education and intensifying collaboration with the practitioners in healthcare units, their patients and target communities.
\end{abstract}

\title{
Keywords
}

Activity theory, expansive learning, formative intervention, change laboratory, healthcare, medical education 


\section{Practice points}

- Expansive learning builds on the cultural-historical activity theory (CHAT) and takes historically formed systemic contradictions as the starting point of the analysis.

- In expansive learning, transformations are understood as zones of proximal development, collective terrains of possibilities between the present and the future.

- At the heart of activity theory -based research are activity systems, the contradictions between them and within them.

- Change Laboratory is a formative intervention method developed for studying workplaces in transition and creating improved, shared patterns of activity.

- Expansive learning provides an excellent theoretical and methodological approach for studying health professions' education in change. 


\section{Introduction}

Physicians work as integral members of the complex social systems of healthcare organisations. Competency-based education frameworks require that medical training develop future physicians' systems-based practice, advocacy, and collaboration (Orsino and Ng 2019). At the same time, a foundational change is going on in the overall object of medicine, namely the spectrum of health problems patients are suffering from and seeking care for. The proportion of elderly people and patients with chronic conditions requiring long-term care is increasing. Patients with multimorbidity, i.e. suffering from two or more chronic conditions, is expanding and utilizing a significant portion of health care resources (Barnet et al. 2012; Braithwaite 2018). At the same time, medical professionals are becoming increasingly aware that poverty and poor health go hand in hand and the socio-economically deprived have limited access to health care.

Fragmentation of patient care is a major challenge for healthcare practice. Healthcare systems are largely designed to treat patients' single symptoms and diseases rather than complicated long-term disorders and the co-occurrence of chronic conditions, mental disorders and poverty (Walker and Druss 2017).

Studies on multimorbidity and fragmentation of care call for medical education to adopt an approach that provides patients with continuity, coordination and collaboration across healthcare units and with patients under their care (Barnet et al. 2012; Braithwaite 2018; Engeström 2018). Still, most medical studies focus on disease-centred specialist perspectives at the expense of comprehensive patient care and collaboration between primary healthcare and specialist care. 
Concurrently, systems of healthcare are increasingly penetrated by market-oriented business calculations and managerialism that favour rapid turnover and short-term profits. The instruments of medicine are becoming framed in terms of rationalization, standardization and commoditization, notions that favour linear and pre-packaged top-down processes and procedures rather than horizontally co-constructed care trajectories and long-term societal impact. These forces make the needed expansion of the object of medicine very difficult.

Fragmentation of patient care and medical education as well as the increasing number of patients with long term conditions and comorbidities require a radical expansion of the object of medicine: longer time perspectives, broader collaborative and interdisciplinary approaches, and transformative agency from medical practitioners and their organizations. Therefore, we need a theoretical and methodological approach designed to investigate transformation, disturbances and controversy.

Cultural-historical activity theory (CHAT) takes historically formed systemic contradictions as the starting point of the analysis. Figure 1 shows how the general model of an activity system (Engeström 2015, p. 63) can be used to construct a working hypothesis of the pervasive contradictions of medical work.

[Figure 1 near here].

Contradictions generate disturbances and conflicts in everyday medical work. On the other hand, they also stimulate everyday innovation and local change (Martin et al. 2017). Thus, 
they challenge the medical social system to understand and manage complexity, to identify the dynamics of contradictions, and to utilize them in emancipatory transformations.

This article introduces key concepts of cultural-historical activity theory and the theory of expansive learning (Engeström 2015; Engeström and Sannino 2010; Engeström 2018).

Expansive learning is a research tradition with strong links between theory, empirical research and formative interventions. Therefore, we discuss activity theory with the help of concrete examples of formative interventions implemented in the context of healthcare where healthcare professionals and patients tackled fragmentation of care and contradictions in the activity systems of medical work.

\section{The zone of proximal development of medical work: Collaborative and transformative expertise}

In activity theory, transformations are not seen as linear moves toward pre-fixed end points. They are understood as zones of proximal development. This concept was originally presented by Vygotsky in the context of individual learning (1978, p. 86). Engeström (2015, p. 138) redefined the concept to address learning and development at the level of collective activities. Zones of proximal development are terrains of possibilities between the present and the future where activities can be collectively transformed as a solution to the contradictions at hand.

To portray a zone of proximal development of an activity such as medical work, we need to identify the key dimensions of historical change and development. In Figure 2, the zone of proximal development of medical expertise is illustrated with the help of two dimensions: 
namely, between an individual and a collective locus of expertise (the vertical dimension), and between learning for stability and learning for change (the horizontal dimension). Together, these two dimensions form a fourfold field in which the historically earliest craft expertise is located in the lower left section and the largely uncharted collaborative and transformative expertise is located in the upper right section.

[Figure 2 near here].

Collaborative and transformative expertise implies that medical practitioners are involved in ongoing systemic change efforts. This can only be accomplished by means of collaboration among healthcare practitioners and coalition-building between healthcare units, their patients and target communities, and other societal actors. As described in Figure 2, we may identify three spearheads toward collaborative and transformative expertise: (1) reconceptualizing expertise as object-oriented and contradiction-driven activity systems, (2) pursuing expertise as negotiated knotworking, and (3) building expertise as expansive learning. We will introduce these three spearheads in the following sections.

\section{Expertise as object-oriented activity systems}

One of the foundational ideas of cultural-historical activity theory is the distinction between short-lived, goal-directed actions and durable and collective activities (Leont'ev 1978). An activity is understood as a collaborative and holistic system that generates actions. An activity system is oriented towards an object. The object embodies the long-term purpose of the activity, generating horizons for possible actions. In healthcare, the general object is health and illness, whereas each specific patient with a specific complaint is a situated manifestation of the object. 
In complex social institutions such as healthcare, there are historically accumulated systemic contradictions within and between the nodes of each activity system, and among interconnected activity systems. One of the major challenges in medical work today is the fragmentation of care, or in activity-theoretical terms, the fragmentation of the object, especially salient in the care of patients with multiple chronic conditions (Kerosuo and Engeström 2003; Engeström 2018; Meijer et al. 2020, in press). Figure 3 portrays the fragmentation of the care of a patient who drifted between several medical specialties and clinics in the health care system of the city of Helsinki in Finland.

[Figure 3 near here].

Fragmentation emerged when (a) the different specialist caregivers concentrated exclusively on the symptoms and care that "belonged" to their own restricted areas of responsibility and competence, (b) there was neither common language nor understanding between the different caregivers, and (c) there was no efficient mechanism that guaranteed coordination, cooperation and communication between the different parties involved in the patient's care. Fragmentation led to gaps and risks of disruption in the care, as exemplified in Excerpt 1.

\section{Excerpt 1}

Patient: My husband died of cancer and my daughter is now sixteen. Being just the two of us, I feel I have to stay alive and protect my kidney by all possible means, to bring her up into adulthood. So that's what causes stress for me. 
Researcher: So the problem is uncertainty in acute situations, whether or not information has been passed from one doctor to the other...

Patient: Yes, if I cannot convey the information myself, like it was in that particular situation recently. I was not able to explain my situation. That's something I have thought about many times...

The fragmentation of care was generated by contradictions between and within activity systems. The activity systems of specialist care in the hospital, general practice in the primary health care, and the patient's own life with ill health each had a different object, and these objects frequently collided and rarely met. The division of labor emphasized solo responsibility of each practitioner, effectively encapsulating the responsibilities of the specialist and the general practitioner. Moreover, these two activity systems operated with specific, separate instruments, whereas a patient with multiple chronic conditions would have needed shared instruments. Furthermore, the market economy rules guided the health care units to prioritize short-term cost-efficiency. This tension-laden constellation is schematically illustrated in Figure 4.

[Figure 4 near here].

\section{Expertise as knotworking}

The second spearhead towards the zone of proximal development of medical work is knotworking. The concept of knotworking was developed in a series of interventions aimed at overcoming fragmentation (Engeström et al. 1999; Engeström 2008). The learning challenge was to seek and establish a new way for practitioners and patients to work between the 
caregiver organizations and collaboratively plan and monitor a patient's care. In healthcare, permanent teams are increasingly replaced by fluid combinations of expertise, "knots" that correspond to the problem at hand (Engeström 2008; Bleakley 2014; Hurlock-Chorostecki et al. 2015; Larsen et al. 2017; Varpio and Teunissen 2020, in press).

The notion of a knot refers to a rapidly pulsating and partially improvized orchestration of collaborative performance between otherwise loosely connected actors and activity systems (Engeström et al. 1999). Knots operate by tying and retying together otherwise separate threads of activity and expertise, involving both rapid improvisation and a long-term perspective of planning and following up. The specific instrumentality of knotworking in healthcare is related to clients or patients as being equal parties in the negotiations and flexible agreements. This requires a shared language and object between the participating actors.

Knotworking is a model for overcoming fragmentation of the object. Practitioners from different specialties and organizations involved in the care of a patient seek ways to negotiate, coordinate and combine their expertise for the best of the patient in various points of the care trajectory. An example of knotworking is the collaborative development and implementation of an instrument called care agreement that contained all relevant information about the patient's care in different units (Engeström 2018). Excerpt 2 gives an example of negotiation of the multi-party care agreement to improve the fragmented care of the patient presented in Excerpt 1.

\section{Excerpt 2}


Chief physician [pointing at a document in front of her]: So, will you [the patient's personal GP] be first, as the physician responsible for her at the primary care health center? And then we will add...

Consulting physician: Here we are kind of documenting what is already in place, but if we had a similar case where these contacts had not yet been created, this would serve as sort of a model from which other patients could benefit.

Chief physician: It would be very important if we had a situation where the patient's personal physician is changed, the previous doctor would go on leave, and the next doctor would come for half a year. In such cases this has great importance, so that the doctor knows...

Chief physician: Please let the patient also sign it, while you are at it. .... From the signatures one sees that there are several people involved....

Engaging in negotiated knotworking is a demanding step in the creation of new tools for negotiated care and collaboration in healthcare. Attempts easily slip back to the traditional forms of communication and coordination among professionals potentially excluding the patient. In Excerpt 2, the chief physician had to remind the other practitioners that also the patient's signature was needed in the care agreement.

\section{Expertise as expansive learning}

Expansive learning provides a unique way of analyzing and promoting learning for change. The theory of expansive learning focuses on learning of new patterns of activity that are not yet there; they are learned as they are designed (Engeström 2015; 2016). The subjects of expansive learning are involved in a multi-voiced learning process in which they struggle, 
negotiate and hybridize between the alternative perspectives and collectively form concepts “in the wild" (Engeström and Sannino 2012).

Expansive learning proceeds by means of learning actions that form cycles of expansive learning (Figure 5). The thickening arrows in the figure indicate increasing momentum in terms of numbers and commitment of participants involved in the process. Cycles of expansive learning sometimes occur without deliberate intervention, but this is rare. A methodology of formative interventions has been developed to trigger, support and analyze cycles of expansive learning (Engeström et al. 2014).

[Figure 5 near here].

A formative intervention method called Change Laboratory was developed in the 1990s for studying organisations and workplaces facing major transformations (Engeström et al. 1996; Engeström and Sannino 2010; Virkkunen and Newnham 2012; Sannino and Engeström 2017). Change Laboratory is aimed at triggering and supporting expansive learning. A Change Laboratory may focus on a local unit, such as a clinic, or bring together multiple activity systems to resolve larger-scale contradictions and tensions.

The Change Laboratory method requires that the researchers collect empirical material, e.g. interviews, observation and video-recordings, from authentic workplace contexts. The material includes critical incidents, disturbances and problems of which the researcher selects and provides extracts for a "mirror" to stimulate involvement, analysis and collaborative 
efforts among participants in Change Laboratory sessions to seek and design new patterns of activity.

A typical Change Laboratory intervention proceeds through six to ten sessions. Participants first view video excerpts selected by the researchers to elicit the learning action of questioning the existing mode of activity. Next, participants discuss the problems, their systemic causes, and possible remedies or solutions - performing historical and empirical analysis. Problems, causes, and suggested solutions are written up on whiteboards or flip charts by a scribe. Then, participants engage in the learning action of modeling, jointly drafting a zone of proximal development and a new model for their activity. The aims and contents of the new model are discussed, and detailed changes and improvement suggestions are made, corresponding to the action of examining and testing the model. Participants plan and execute practical changes in the activity, corresponding to the learning action of implementing the model. The process is assessed by examining the work accomplished in an action of reflecting on the process. Consolidation and generalization of the outcomes are initiated toward the end of a Change Laboratory intervention and typically continue after it.

A Finnish study on the development of a negotiated way of working between primary health care and specialized hospital care in Helsinki (Engeström et al. 2003; Engeström 2018) provides a rich description of a successful implementation of Change Laboratory in healthcare settings. Data were gathered on the fragmentation of patient care between primary and secondary care in the real-life contexts, nine Change Laboratory sessions were conducted and ten patient cases were jointly analyzed in successive sessions with the patients and the practitioners involved in their care. 
In multiple cycles of expansive learning, practitioners and patients generated a new instrument called the care agreement initiated by a physician who noticed fragmentation in the care of a patient with multiple chronic illnesses (Kerosuo and Engeström 2003). The first draft of the agreement was negotiated between the initiating physician and the patient. The draft was then sent to other healthcare practitioners involved in the patient's care and negotiated among the parties. The care agreement summarized the diagnoses and key concerns of the different subjects and outlined their plans of care. It also explicated the ways they kept each other up-to-date when new developments occurred and changes were made. The care agreement was signed by the key parties, including the patient. Two additional instruments, important in the care agreement instrumentality were developed, namely that of a care map and a care calendar of the patient. Both were collaboratively constructed and negotiated by the physicians and the patients.

Expansive learning cycles may be identified and supported at three levels. To generate and implement a new foundational model between interconnected activity systems in patient care typically takes several years (e.g., Engeström et al. 2007). An intermediate level consists of a focused local transformation with the help of a Change Laboratory intervention, requiring several months (e.g., Engeström et al. 2013). The smallest scale of mini-cycles of expansive learning consist of single intervention sessions or similar restricted episodes (e.g., Nummijoki et al. 2018).

Change Laboratory interventions have been carried out and reported in various medical settings in Finland (Engeström 2018), Denmark (Skipper et al. 2016), Brazil (Vilela et al. 
2020; Grilo Diniz et al. 2020, in press) and the United Kingdom (Reid et al. 2015; Morris et al. 2020, in press).

\section{Lessons for medical education}

This article introduces activity theory and the theory of expansive learning in the context of medical education (Engeström 2015; Engeström 2018). Expansive learning provides a conceptual framework for analyzing the complexities and contradictions of systems of health care and methods for formative interventions where the participants in different healthcare units and patients work together to find new, creative solutions to the tensions and obstacles they face. This type of approach is particularly well suited for exploring the challenges healthcare is facing (Barnet et al. 2012; Braithwaite 2018; Engeström 2018; Bleakley 2020, in press).

In the landscape of transition toward collaborative and transformative expertise, medical education becomes co-responsible for shaping future medical practice. Medical practice can only evolve in response to the needs of the broader communities within which it operates. Beyond classrooms, medical students should increasingly receive education in authentic healthcare settings where patients are treated comprehensively and practitioners advocate for their holistic care. Correspondingly, all medical practitioners in workplaces become medical educators. This can only be achieved by intensifying collaboration and communication between the interconnected activity systems of healthcare, its client communities, and medical education. 
A new prototype and paradigm of medical education will emerge, namely a transformation coalition between target communities, healthcare organizations, medical schools, students, healthcare professionals, patients and other stakeholders (Coburn and Penuel 2016; Sannino 2020). The methodology of formative interventions, especially the Change Laboratory method, may serve as an important resource for building and analyzing such transformation coalitions (Sannino et al. 2016). Interventionist research in these new forms of medical education is urgently needed.

\section{Declaration of interest}

The authors report no conflict of interest. The authors alone are responsible for the content and writing of this article.

\section{Notes on contributors}

Yrjö Engeström is a Professor Emeritus of Adult Education at the University of Helsinki, Finland, and a Professor Emeritus of Communication at the University of California, San Diego, USA. He is a leading figure in cultural-historical Activity Theory and has developed expansive learning, a formative interventionalist approach to study organisations and expertise in transition. He is the author of several books on activity theory and expansive learning, including Expertise in Transition: Expansive Learning in Medical Work (Engeström 2018).

Eeva Pyörälä is a Senior Lecturer in University Pedagogy at the University of Helsinki, Finland, and a Fellow of AMEE. Her scholarly work focuses on mobile learning and digitality in health professions education and communication in healthcare. 


\section{ORCID}

Yrjö Engeström https://orcid.org/0000-0002-6949-4278

Eeva Pyörälä https://orcid.org/0000-0002-2474-2434

\section{References}

Barnett K, Mercer SW, Norbury M, Watt G, Wyke S, Guthrie B. 2012. Epidemiology of multimorbidity and implications for health care, research, and medical education: a crosssectional study. Lancet. 380:37-43.

Bleakley A. 2014. Theorizing team process through cultural-historical activity theory (CHAT): Networking and knotworking. In: Bleakley A. Chapter 10, Patient-centred medicine in transition, p. 139-147. Springer, Cham.

Bleakley A. 2020, in press. Embracing ambiguity: Curriculum design and activity theory. Med Teach.

Braithwaite J. 2018. Changing how we think about healthcare improvement. BMJ. 361:k2014.

Coburn CE, Penuel WR. 2016. Research-practice partnerships in education: Outcomes, dynamics, and open questions. Educ Res. 45(1):48-54. 
Engeström Y. 2008. From teams to knots: Activity-theoretical studies of collaboration and learning at work. Cambridge: Cambridge University Press.

Engeström Y. 2015. Learning by expanding: An activity-theoretical approach to developmental research. 2nd ed. New York: Cambridge University Press.

Engeström Y. 2016. Studies in expansive learning: Learning what is not yet there. New York: Cambridge University Press.

Engeström Y 2018. Expertise in transition: Expansive learning in medical work. Medical work in transition: Towards collaborative and transformative expertise. New York: Cambridge University Press.

Engeström Y, Engeström R, Vähäaho, T. 1999. When the center does not hold: The importance of knotworking. In: Chaiklin S, Hedegaard M, Jensen UJ, Editors. Activity theory and social practice. Aarhus: Aarhus University Press.

Engeström Y, Engeström R, Kerosuo H. 2003. The discursive construction of collaborative care. Appl Linguist. 24(3):286-315. 
Engeström Y, Kerosuo H, Kajamaa A. 2007. Beyond discontinuity: expansive organizational learning remembered. Manag Learn. 38(3):319-336.

Engeström Y, Pihlaja J, Helle M, Virkkunen J, Poikela R. 1996. The change laboratory as a tool for transforming work. Lifelong Learning in Europe. 1(2):10-17.

Engeström Y, Rantavuori J, Kerosuo H. 2013. Expansive learning in a library: Actions, cycles and deviations from instructional intentions. Vocat Learn. 6(1):81-106.

Engeström Y, Sannino A 2010. Studies of expansive learning: Foundations, findings and future challenges. Educ Res Rev. 5(1):1-24.

Engeström Y, Sannino, A. 2012. Whatever happened to process theories of learning? Learn Cult Soc Inter. 1(1):45-56.

Engestrom Y, Sannino A, Virkkunen J. 2014. On the methodological demands of formative interventions. Mind Cult Act. 21(2):118-128.

Grilo Diniz CS, Castro Bussadori JC, Lemes Luana B, Dantas Moisés EC, de Campos Prado CA, McCourt C. 2020, in press. A Change Laboratory for maternity care in Brazil: pilot implementation of MotherBaby Friendly Birthing Initiative. Med Teach. 
Hurlock-Chorostecki C, van Soeren M, MacMillan K, Sidani S, Donald F, Reeves S. 2015. Nurse practitioner interactions in acute and long-term care: An exploration of the role of knotworking in supporting interprofessional collaboration. BMC Nurs 14:50.

Kerosuo H, Engeström Y. 2003. Boundary crossing and learning in creation of new work practice. J Workplace Learn. 15:345-351.

Larsen DP, Wesevich A, Lichtenfeld J, Artino Jr AR, Brydges R, Varpio, L. 2017. Tying knots: an activity theory analysis of student learning goals in clinical education. Med Educ. 51(7):687-698.

Leont'ev AN. 1978. Activity, consciousness, and personality. Englewood Cliffs: PrenticeHall.

Martin GP, Kocman D, Stephens T, Peden CJ, Pearse RM. 2017. Pathways to professionalism? Quality improvement, care pathways, and the interplay of standardisation and clinical autonomy. Sociol Health Illn. 39(8):1314-1329.

Meijer L, de Groot E, Honing-de Lange G, Kearney G, Schellevis F, Damoiseaux R. 2020, in press. Transcending boundaries for collaborative patient care. Med Teach. 
Morris C, Reid A-M, Ledger A, Teodorczuk A. 2020, in press. Expansive learning in medical education: putting Change Laboratory to work. Med Teach.

Nummijoki J, Engeström Y, Sannino A. 2018. Defensive and expansive cycles of learning: A study of home care encounters. Journ Learn Sci. 27(2):224-264.

Orsino A, Ng S. 2019. Can adaptive expertise, reflective practice, and activity theory help achieve systems-based practice and collective competence? Can Med Educ Journ. 10(3):e5560.

Reid AM, Ledger A, Kilminster S, Fuller R. 2015. Can the tools of activity theory help us in advancing understanding and organisational change in undergraduate medical education? Adv Health Sci Educ Theory Pract. 20(3):655-668.

Sannino A. 2020. Enacting the utopia of eradicating homelessness: Toward a new generation of activity-theoretical studies of learning. Stud Contin Educ. Published online:1-17

Sannino A, Engeström Y, Lemos M. 2016. Formative interventions for expansive learning and transformative Agency. J Learn Sci. 25:(4): 599-633. 
Sannino A, Engeström YHM. 2017. Co-generation of societally impactful knowledge in change laboratories. Manag Learn. 48(1):80-96.

Skipper M, Musaeus P, Nøhr SB. 2016. The paediatric change laboratory: Optimising postgraduate learning in the outpatient clinic. BMC Med Educ. 16(1):42.

Varpio L, Teunissen P. 2020, in press. Reformulating leadership in interprofessional healthcare teams: How knotworking requires followership. Med Teach.

Vilela RAG, Querol MAP, Silva-Macaia AA, Hurtado SLB. 2020. Learning in and from Change Laboratory interventions for developing workers' health in Brazil. In: Vilela R, Pereira Querol M, Beltran Hurtado S, Cerveny G, Lopes M, editors. Collaborative development for the prevention of occupational accidents and diseases. Cham: Springer; $p$. 225-253.

Virkkunen J, Newnham DS, Editors. 2012. The change laboratory: A tool for collaborative development of work and education. Rotterdam: Sense publishers.

Vygotsky LS. 1978. Mind in Society: The development of higher psychological processes. Cambridge, MA: Harvard University Press. 
Walker ER, Druss BG. 2017. Cumulative burden of comorbid mental disorders, substance use disorders, chronic medical conditions, and poverty on health among adults in the USA. Psychol, Health Med. 22(6):727-735. 


\section{List of captions for figures}

Figure 1. Pervasive contradictions in medical work (the double-headed and lightning-shaped arrows indicate key contradictions).

Figure 2. Zone of proximal development of medical expertise (Engeström 2018, p. 256).

Figure 3. Care map explicating the fragmentation of the care of a patient with multiple chronic conditions (Engeström 2018, p. 224).

Figure 4. Systemic contradictions as sources of fragmentation of care of patients with multiple chronic conditions (see legend to Figure 1 for explanation of symbols).

Figure 5. Cycle of expansive learning (Engeström and Sannino 2010, p. 8). 
Figure 1. Pervasive contradictions in medical work (the double-headed and lightning-shaped arrows indicate key contradictions).

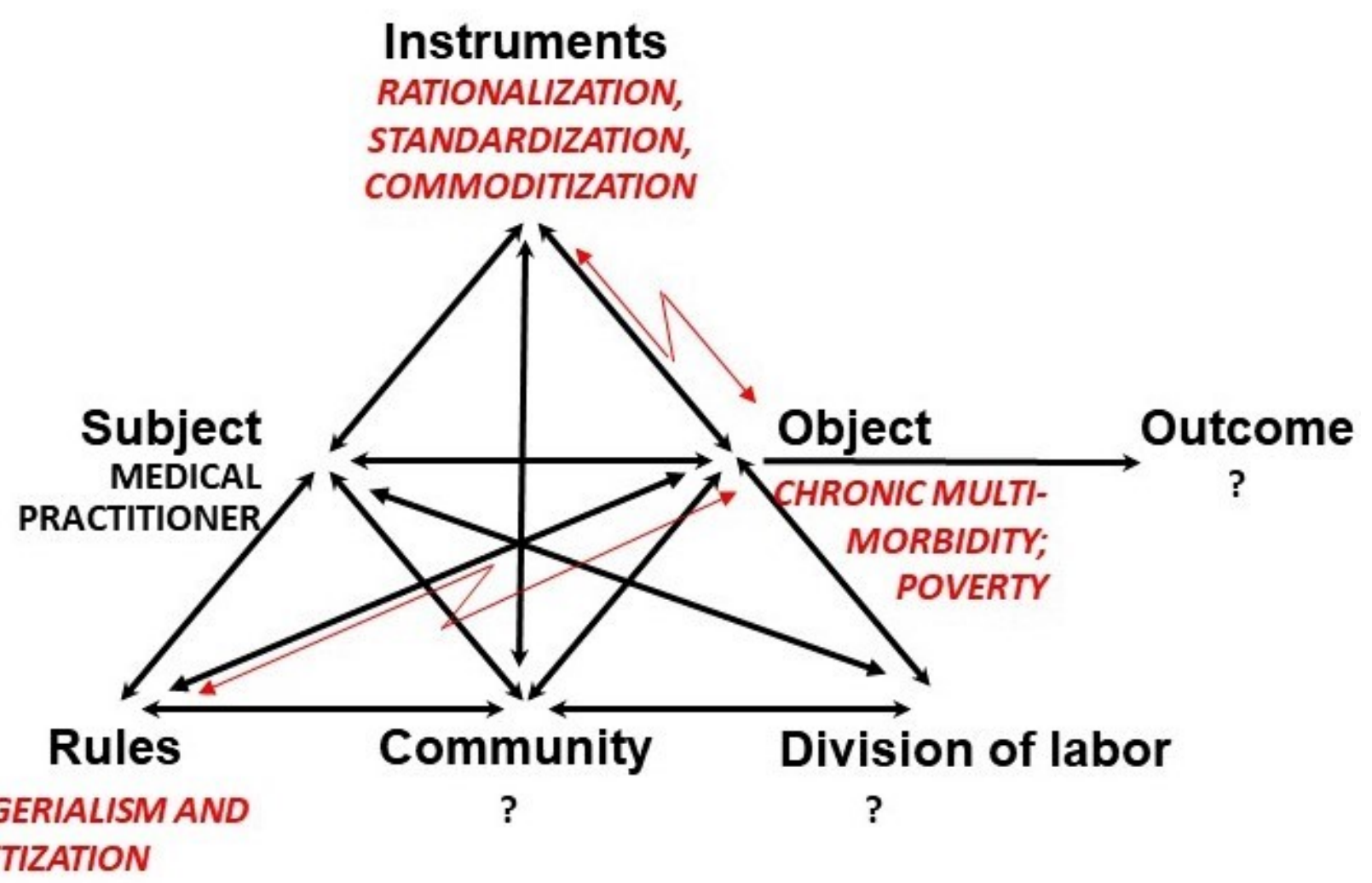


Figure 2. Zone of proximal development of medical expertise (Engeström 2018, p. 256).

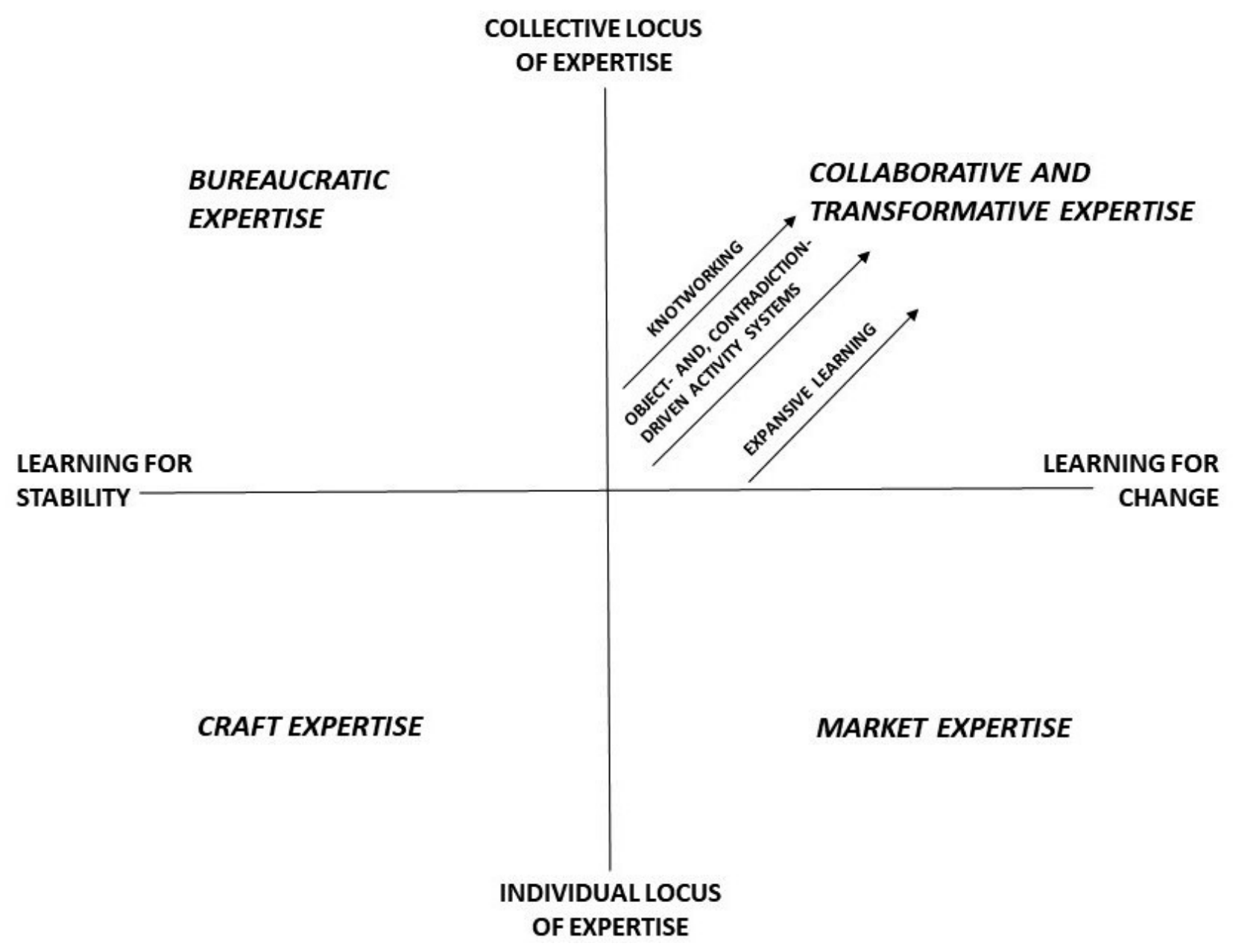


Figure 3. Care map explicating the fragmentation of the care of a patient with multiple chronic conditions (Engeström 2018, p. 224).
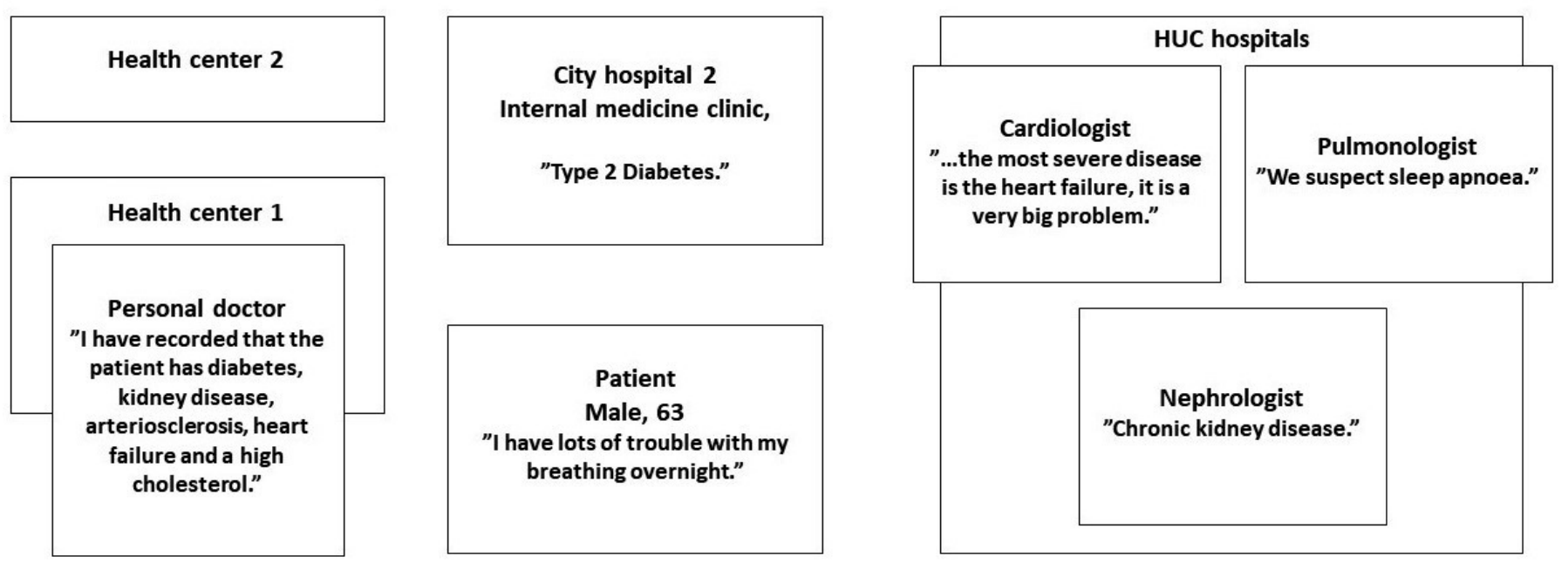
Figure 4. Systemic contradictions as sources of fragmentation of care of patients with multiple chronic conditions (see legend to Figure 1 for explanation of symbols).

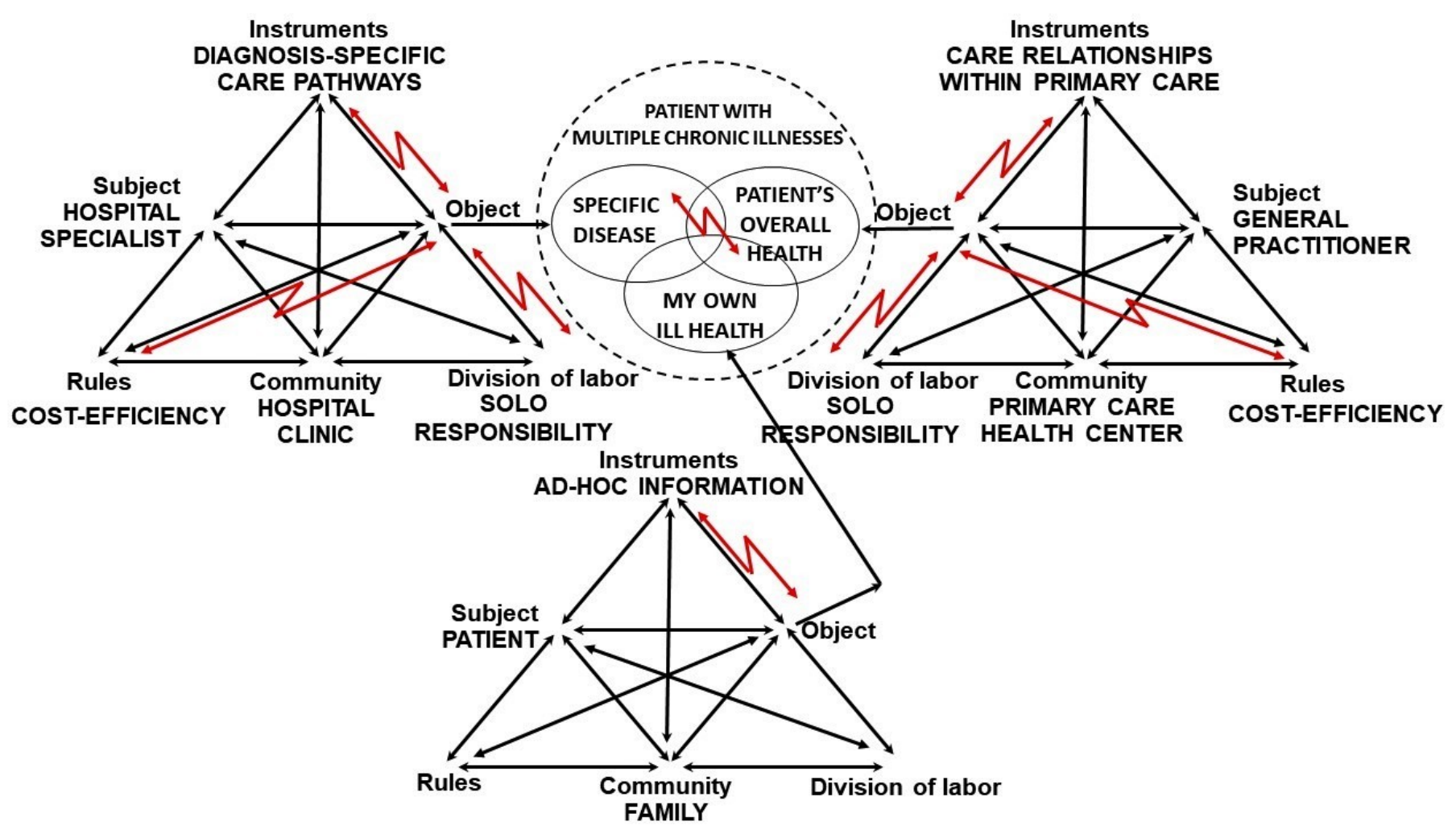


Figure 5. Cycle of expansive learning (Engeström and Sannino 2010, p. 8).

\section{CONSOLIDATING AND}

GENERALIZING THE NEW PRACTICE

6. REFLECTING ON THE

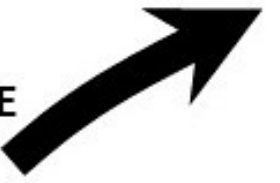
PROCESS

1. QUESTIONING
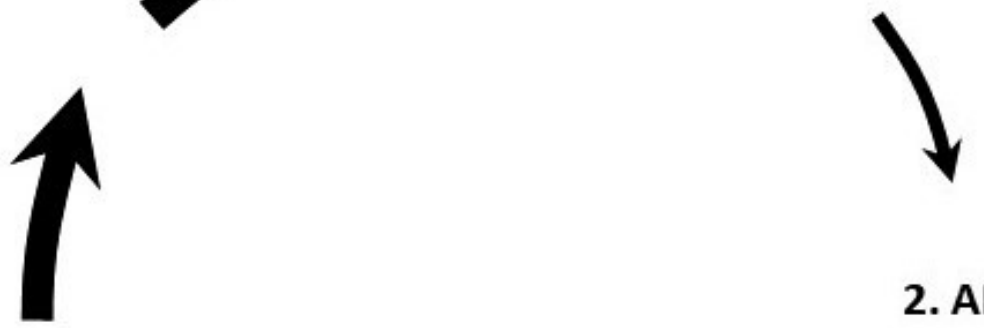

2. ANALYSIS

5. IMPLEMENTING THE NEW MODEL
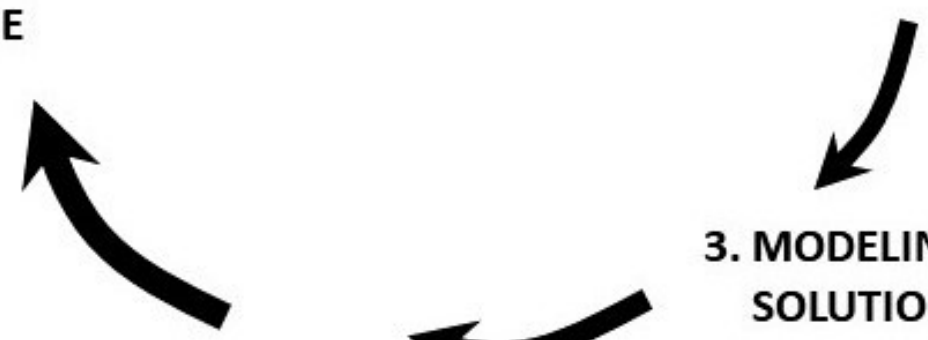

3. MODELING THE NEW

4. EXAMINING

AND TESTING THE NEW MODEL SOLUTION 